\title{
Breast Pain, CTCAE 5.0
}

National Cancer Institute

\section{Source}

National Cancer Institute. Breast Pain, CT CAE 5.0. NCI Thesaurus. Code C146742.

A disorder characterized by a sensation of marked discomfort in the breast region. 